\title{
Demographic and prosocial intrapersonal characteristics of biobank participants and refusers: the findings of a survey in the Netherlands
}

\author{
Reinder Broekstra $\mathbb{I}^{1,3} \cdot$ Judith Aris-Meijer ${ }^{1} \cdot$ Els Maeckelberghe $\mathbb{I}^{2} \cdot$ Ronald Stolk $^{1} \cdot$ Sabine Otten ${ }^{3}$
}

Received: 23 December 2019 / Revised: 3 June 2020 / Accepted: 7 July 2020 / Published online: 31 July 2020

(c) The Author(s) 2020. This article is published with open access

\begin{abstract}
Research in genetics relies heavily on voluntary contributions of personal data. We aimed to acquire insights into the differences between participants and refusers of participation in a Dutch population-based biobank. Accordingly, we assessed the demographic and prosocial intrapersonal characteristics of respondents who participated $(n=2615)$ or refused to participate $(n=404)$ in the Lifelines biobank and databank. Our results indicated that health-related values critically influence participation decisions. The participation threshold for Lifelines was determined by an absence of health-related values and of trust in government. Therefore, considering these factors in communication and recruitment strategies could enhance participation in biomedical research. No indications were found of a stronger general prosociality of participants or their trust in researchers beyond the context of biobanking. This emphasizes the contextual understanding of the decision of participation in biobanking. Our findings may contribute to improving recruitment strategies by incorporating relevant values and/or highlighting prosocial benefits. Moreover, they foreground the need to address trust issues in collaborations between data repositories and commercial companies. Future research should explore how prosocial intrapersonal characteristics drive participation and withdrawal decisions and relate to contextual attributes.
\end{abstract}

\section{Introduction}

Genetic and biomedical research rely heavily on voluntary contributions of personal data [1]. Simultaneously, an increase in calls for data has led to mounting concerns about data security and privacy [2]. These concerns might lead to lower willingness to participate in biomedical research [3-6]. Therefore, a study of the differences between those who accept and decline invitations to participate in a

Supplementary information The online version of this article (https:// doi.org/10.1038/s41431-020-0701-1) contains supplementary material, which is available to authorized users.

Reinder Broekstra

r.broekstra@umcg.nl

1 Department of Epidemiology, University Medical Center Groningen, University of Groningen, Groningen, The Netherlands

2 Wenckebach Institute for Medical Education and Training, University Medical Center Groningen, University of Groningen, Groningen, The Netherlands

3 Department of Social Psychology, Faculty of Behavioral and Social Sciences, University of Groningen, Groningen, The Netherlands biobank could yield valuable insights into effective strategies for recruiting participants [7].

Studies have identified various factors that indicate whether people are willing to participate in biobanks or not. There is ample evidence that several demographic characteristics are associated with the intention to participate in biobanks, e.g., being highly educated [8-11], having a partner [6, 12], being non-religious $[10,13]$ and having better (self-reported) health $[8,14]$. Other demographic characteristics are more inconsistently associated, such as being older $[3,8,15]$ or younger $[10,11]$ vs. no age-effect $[9,16,17]$; being male $[3,17]$ or female [16] vs. no gender effect $[9,10]$.

Psychological characteristics, such as trust in and concern for others, provide a stable pattern of associations with willingness to participate. Studies report that participation willingness in biobanks is strongly associated with having greater societal trust [3, 8], with higher levels of social engagement [18] and with being registered as organ or blood donor [8]. Societal trust refers to a generalized trust in the government as system or institution [19], and in unknown other citizens [20]. Other strong associations with participation have been found for factors specific to the biobanking domain, such as trust in biobanks $[6,9]$ or positive attitudes towards biobanking in general [3, 21, 22], and towards biomedical research [21, 22]. 
Attitudes, values and behaviours reflecting cooperative tendencies and confidence in cooperation-which we here summarize as prosocial intrapersonal characteristicsindependently contributed to willingness to participate in biobanking $[9,21]$. The key role of these prosocial characteristics is in line with studies emphasizing the importance of prosocial motives for participation in biobanking $[3,4,23]$. Moreover, similar associations were found for prosocial characteristics with decisions about cooperation in other societal contexts, for example, participation in voluntary work [24] or in smart energy systems [25]. Especially, societal trust and domain-specific values, e.g. concern for environment, proofed to be robust predictors in these contexts [26-28].

Furthermore, psychological characteristics seem to explain non-participation, and in particular refusal, better than demographic characteristics. For example, a study in the USA found that women and older patients were more likely to respond to recruitment, but these demographics were not associated with refusal. Instead, people refusing participation in biobanking looked, just as participants, more often and more actively for information about biobanking than non-participants not responding to recruitment request, while participants as well as both non-participant groups had the same prior knowledge [16].

It is possible that thresholds for participation arise due to competing values about society or concerns about biobanking. A recent study in Finland showed that donating blood for biobanking purposes was perceived with more concerns than donating blood for treatment of patients [29]. Trust reduced complexity of decisions about participation by perceiving fewer risks $[19,30]$. A lack of trust indicates an increased anxiety about harm [31]. This anxiety may be exacerbated when sharing data with biobanks, in particular involving commercial enterprises or researchers. Studies showed that refusal in biobanking is related to societal and individual concerns, such as fear of discovering possible genetic predisposition to certain diseases leading to social stigma [21]; worry that information may be used against personal interest resulting into discrimination [16, 21, 30]; or concerns about commercial purposes eventually derogating public goods $[21,23,30]$.

Together, the evidence summarized above suggests that psychological characteristics could be relevant predictors of both participation and refusal in biobanking. We investigated people who either participated or explicitly refused to participate in a Dutch population-based biobank. We aimed to contribute insights into (non-)participation in biobanking by simultaneously investigating demographic and prosocial intrapersonal characteristics to elucidate their independent roles in the decision to participate or refuse participation, regardless of the motives for these decisions.

\section{Materials and methods}

\section{Procedure and participants}

We conducted an online survey of a sample of the general population in the Northern provinces of the Netherlands ( $n$ =3019), comprising 2615 participants in a Dutch biobank, and 404 citizens who refused or signalled refusal to contribute to Lifelines or similar large-scale centralized data repository for scientific medical research. Our sample of participants was recruited via Lifelines in May 2018. The response rate for the invitation of this additional study was $22.2 \%$ without incentives. Lifelines recruited its participants between 2006 and 2013 from the general population in the northern provinces of the Netherlands, and providing a representative sample $(n=167,000)$ [12, 32]. Our sample of refusers was recruited among a representative respondents' panel of the Northern Dutch population via the DirectResearch EUpanel $(n=30,600)$ in August of the 2018. These respondents received a small financial incentive for their studies, resulting in a response rate of $41.4 \%$, respectively. Both organizations applied the same recruitment protocol and stratified the samples for sex and age. The subsample of biobank participants was provided by Lifelines themselves, since they exclusively recruit data from their participants. These participants consented between 2006 and 2013 to participate in a longitudinal prospective cohort study of onset, risk factors and course of chronical diseases [32]. Refusers stemmed from the DirectResearch sample from the northern general population. Self-reported refusal was measured via two items at the beginning of our questionnaire. First, these were people who indicated that they did not participate "in large scale medical scientific studies, for example Lifelines" $(n=$ 1738). Next, within this broader sample of non-participants, we identified refusers via their affirmation of the statement "I did not want/would not want to participate in this type of research" $(n=404)$. The mean age of Lifelines' respondents was $56(\mathrm{SD}=15.88)$ with $50.5 \%$ being male, whereas the mean age of DirectResearch' respondents after exclusion was $56(\mathrm{SD}=14.18)$ with $48.5 \%$ being male (Table 1 and Supplementary Table 1).

\section{Measures}

\section{Demographic characteristics and self-reported health}

We measured previously identified demographic characteristics associated with participation or willingness to participate in a biobank, such as marital status [6, 12], education level [8-11], religion $[10,13]$, residential areas 
Table 1 Demographic characteristics and self-reported health of participants and refusers of a Dutch population-based biobank.

\begin{tabular}{|c|c|c|c|c|c|}
\hline \multirow[b]{2}{*}{ Age } & \multicolumn{2}{|c|}{ Participants } & \multicolumn{2}{|c|}{ Refusers } & \multirow{2}{*}{$\frac{p}{=0.83}$} \\
\hline & 56.27 & $(15.88)$ & 56.09 & $(14.18)$ & \\
\hline Gender & & & & & $=0.47$ \\
\hline Male & 1291 & $(50.5 \%)$ & 179 & $(48.5 \%)$ & \\
\hline Female & 1264 & $(49.5 \%)$ & 190 & $(51.5 \%)$ & \\
\hline Marital status & & & & & $\leq 0.01$ \\
\hline Registered partner & 2078 & $(79.5 \%)$ & 269 & $(66.6 \%)$ & \\
\hline No registered partner & 536 & $(20.5 \%)$ & 134 & $(33.4 \%)$ & \\
\hline Educational level & & & & & $\leq 0.01$ \\
\hline High & 1083 & $(41.4 \%)$ & 189 & $(46.8 \%)$ & \\
\hline Moderate & 938 & $(35.9 \%)$ & 50 & $(37.1 \%)$ & \\
\hline Low & 559 & $(21.7 \%)$ & 60 & $(14.9 \%)$ & \\
\hline Paid Job & 1460 & $(55.8 \%)$ & 205 & $(50.7 \%)$ & $=0.07$ \\
\hline Religious & 972 & $(37.2 \%)$ & 140 & $(34.7 \%)$ & $=0.48$ \\
\hline Residence & & & & & $=0.04$ \\
\hline Rural & 2019 & $(77.2 \%)$ & 295 & $(73.0 \%)$ & \\
\hline Urban & 537 & $(20.5 \%)$ & 102 & $(25.2 \%)$ & \\
\hline $\begin{array}{l}\text { Self-reported health }(1= \\
\text { very poor, } 5=\text { very good })\end{array}$ & 3.97 & $(0.71)$ & 3.71 & $(0.74)$ & $\leq 0.01$ \\
\hline
\end{tabular}

The values shown in the table are either means with standard deviations or numbers $(n)$ with percentages $(\%)$ relating to the total sample or mean values with standard deviations.

[12] and self-reported general health [8, 14]. Work status was included as additional indicator of socioeconomic status.

\section{Prosocial intrapersonal characteristics}

\section{Prosocial orientation and values}

We applied two measures to determine respondents' prosocial orientations. The first was their actual prosocial behaviour reflected in their organ and blood donor status and the frequency of their charitable donations. The second was the degree to which respondents cared about others' outcomes in resource allocation choices, which was measured using six key items of the Social Value Orientation (SVO) scale. This scale is designed to measure the magnitude of individuals' general concern for others [33]. Replicating previous research, our results indicated excellent reliability with $\alpha>0.90$ [34].

We used eleven items based on the theory of basic values to assess motivations of self-interest and beyond [35]. Moreover, we applied an adapted version of the Environmental Personal Values Questionnaire (E-PVQ) scale [26]. Although our focus primarily was on behaviour in the context of healthcare, we investigated values related to a wider context, e.g., about the environment. This might distinguish individuals acting based on their general concern for others, themselves and a common environment. In addition to the original subscales measuring hedonic values (individual pleasure, e.g., "it is important to have fun") and biospheric values (concern about the environment, e.g., "it is important to protect the environment"), we included a subscale on healthspheric values (health and healthcare concerns, e.g. "it is important to live a fit life"). The reliability was good with $\alpha>0.80$ on all subscales, but they had a strong intercorrelation (Table 2).

\section{Societal trust}

Societal trust was measured based on the framework proposed by Mayer et al. [36]. We used six items reflecting trust in the government and trust in other citizens on a fivepoint Likert-scale, e.g., "the government can take care of her citizens"; "the government acts with good intentions"; "people are trustworthy". The six items tap into various aspects of societal trust, namely, competence, good intentions, and trustworthiness [36]. The combined scale had a good reliability ( $\alpha=0.86$ ).

In addition, five items measured trust in a domainspecific way (i.e., referring to large-scale data repository), namely, trust in different types of research organizations their data management and handling (i.e., hospital, government, university, large-sized commercial enterprises, and medium-sized enterprises (SMEs)). For example, we used items "I believe that the hospital correctly, adequately and fairly store and treat my personal data". Besides trust in organizations as entity, we measured trust in specific common research employees their data management and handling with four items (i.e., hospital researcher, university researcher, market researcher, polling researcher). For example, an item was "I trust employees of the hospital conducting research with a correct, fair and careful approach". We conducted a principal component analysis with an oblimin rotation, due to several high intercorrelations $(r>0.50)$. The analysis showed that the items could be reduced to three factors explaining $71.90 \%$ of the total variance. The first factor, with four items, was labelled "Trust in data management and handling of government" (including researchers' data practices within its institutes) and explained $45.74 \%$ of the total variance $(\alpha=0.83)$. The second factor, "Trust in data management and handling of commercial organizations", comprised two items and explained $14.24 \%$ variance $(\alpha=0.65)$. The third factor, "Trust in data management and handling of commercial researchers", comprised two items and explained $11.92 \%$ of the total variance $(\alpha=0.47)$. Table 2 shows that the correlations between components were low to moderate $(r<$ $0.40)$.

\section{Data analysis}

We calculated descriptive statistics for demographic and psychological variables, applying the chi-square test or 
Table 2 Correlation table.

\begin{tabular}{|c|c|c|c|c|c|c|c|c|c|c|c|c|}
\hline Variable & 1 & 2 & 3 & 4 & 5 & 6 & 7 & 8 & 9 & 10 & 11 & 12 \\
\hline 1. Age & 1 & & & & & & & & & & & \\
\hline $\begin{array}{l}\text { 2. Educational level }(1= \\
\text { low, } 2=\text { moderate, } 3= \\
\text { high })\end{array}$ & -0.21 & 1 & & & & & & & & & & \\
\hline 3. Self-reported health & -0.07 & 0.15 & 1 & & & & & & & & & \\
\hline $\begin{array}{l}\text { 4. Frequency of } \\
\text { charitable donations }\end{array}$ & 0.16 & 0.06 & $0.05^{\mathrm{S}}$ & 1 & & & & & & & & \\
\hline $\begin{array}{l}\text { 5. Social Value } \\
\text { Orientation score }\end{array}$ & 0.01 & 0.06 & 0.02 & 0.15 & 1 & & & & & & & \\
\hline 6. Healthsperic values & 0.17 & -0.02 & 0.26 & 0.14 & 0.12 & 1 & & & & & & \\
\hline 7. Hedonic values & $-\mathbf{0 . 0 7}$ & -0.05 & 0.16 & 0.07 & 0.09 & 0.71 & 1 & & & & & \\
\hline 8. Biospheric values & 0.23 & -0.01 & 0.12 & 0.18 & 0.14 & 0.73 & 0.54 & 1 & & & & \\
\hline 9. Societal trust & 0.02 & 0.22 & 0.22 & 0.18 & 0.13 & 0.20 & 0.13 & 0.17 & 1 & & & \\
\hline 10. TDM\&H/government & $-0.04^{\mathrm{S}}$ & 0.11 & 0.12 & 0.11 & 0.12 & 0.19 & 0.19 & 0.16 & 0.42 & 1 & & \\
\hline $\begin{array}{l}\text { 11. TDM\&H/commercial } \\
\text { enterprises }\end{array}$ & 0.06 & -0.14 & 0.03 & 0.07 & 0.05 & 0.05 & 0.01 & 0.02 & 0.24 & 0.34 & 1 & \\
\hline $\begin{array}{l}\text { 12. TDM\&H/commercial } \\
\text { researchers }\end{array}$ & $0.04^{\mathrm{S}}$ & 0.05 & 0.07 & 0.09 & 0.08 & 0.02 & -0.01 & $0.04^{\mathrm{S}}$ & 0.34 & 0.47 & 0.40 & 1 \\
\hline
\end{tabular}

Bold is significant with $p<0.01$; bold ${ }^{\mathrm{S}}$ is significant with $p<0.05$.

independent $t$-tests to calculate differences in means between participants and refusers where appropriate. We performed multivariate binary logistic regression analyses with a manual entering strategy to build respondents' profiles based on their psychological characteristics while controlling for demographic characteristics. All analyses were conducted using SPSS, Version 25.0 [37].

\section{Results}

\section{Demographic characteristics and self-reported health}

Table 1 shows that more participants than refusers had registered partnerships including marriages (79.5 vs. $66.6 \%$, $p<0.01)$. There was a positive though non-significant trend for having a job (55.8 vs. 50.7\%, $p=0.07)$. While participants reported better general health status (3.97 vs. 3.71, $p<$ 0.01 ), refusers had a higher educational level (46.8 vs. $41.4 \%$, $p<0.01$ ), were more commonly urban dwelling (77.2 vs. $73 \%, p<0.01)$ and less religious (37.2 vs. $34.7 \%, p<0.01)$.

\section{Prosocial intrapersonal characteristics}

\section{Prosocial orientation and values}

Table 3 shows that compared to refusers, participants were more commonly contributors to charities $(2.68$ vs. $2.44, p<0.01)$, blood donors $(11.7$ vs. $5.4 \%, p<0.01)$ and
Table 3 Prosocial intrapersonal characteristics of participants and refusers of the Lifelines biobank.

\begin{tabular}{llllll}
\hline & \multicolumn{2}{l}{ Participants } & \multicolumn{2}{l}{ Refusers } & $p$ \\
\hline $\begin{array}{l}\text { Frequency of donations to } \\
\text { charities }\end{array}$ & 2.68 & $(1.08)$ & 2.44 & $(1.04)$ & $\leq 0.01$ \\
Blood donor & 306 & $(11.7 \%)$ & 22 & $(5.4 \%)$ & $\leq 0.01$ \\
Organ donor & 1460 & $(55.8 \%)$ & 149 & $(36.7 \%)$ & $\leq 0.01$ \\
Social Value & 32.25 & $(14.19)$ & 29.94 & $(13.85)$ & $\leq 0.01$ \\
Orientation score & & & & & \\
Values & & & & & \\
$\quad$ Healthspheric & 3.99 & $(0.66)$ & 3.73 & $(0.73)$ & $\leq 0.01$ \\
$\quad$ Hedonic & 4.25 & $(0.65)$ & 4.09 & $(0.70)$ & $\leq 0.01$ \\
$\quad$ Biospheric & 3.76 & $(0.75)$ & 3.83 & $(0.75)$ & $\leq 0.01$ \\
$\begin{array}{l}\text { Societal trust } \\
\text { TDM\&H/government }\end{array}$ & 3.25 & $(0.63)$ & 3.02 & $(0.74)$ & $\leq 0.01$ \\
$\begin{array}{l}\text { TDM\&H/commercial } \\
\text { enterprises }\end{array}$ & 2.82 & $(0.54)$ & 3.62 & $(0.71)$ & $\leq 0.01$ \\
$\begin{array}{l}\text { TDM\&H/commercial } \\
\text { researchers }\end{array}$ & 3.34 & $(0.73)$ & 2.74 & $(0.76)$ & $=0.81$ \\
\hline
\end{tabular}

The values in the table are either means with standard deviations or numbers $(n)$ with percentages $(\%)$ relating to the total sample.

$T D M \& H$ trust in data management and (data) handling.

organ donors (55.8 vs. $36.7 \%, p<0.01)$. This finding reflects the stronger concerns about others among participants, as indicated by their SVO scores compared with refusers' scores $(32.25$ vs. 29.95, $p<0.01)$. Moreover, they appeared to be more concerned about health, a healthy lifestyle (3.99 vs. $3.75, p<0.01)$, and their own 
pleasure $(4.25$ vs. $4.09, p<0.01)$ than about their environment $(3.76$ vs. $3.83, p<0.01)$.

\section{Societal trust}

Participants had higher levels of trust in the government and in other citizens compared to refusers (3.25 vs. $3.14, p<$ 0.01 ), especially regarding the government's management and handling of data including researchers' data management practices within its institutes $(3.82$ vs. $3.62, p<0.01)$. However, participants were less trusting of researchers' data handling and management practices within commercial enterprises $(3.34$ vs. $3.44, p<0.01)$. There was no difference in levels of trust concerning commercial enterprises among participants and refusers $(2.73$ vs. $2.74, p>0.50)$.

\section{Main analysis}

We started our main analysis by testing the assumptions of our logistic regression, which were all met. First, there were no indications of multicollinearity; all VIF scores were $<10.0$ [38]. Second, some of the continuous variables showed a non-linear relationship of the independent variable to their log odds, as shown by the Box Tidwell test [39]. These variables were adjusted for their non-linear relationship as long as the model fit significantly improved (Table 4). Lastly, the sample size was considered sufficient applying the rule of thumb suggested by Peduz and collaborators of $n>10 \times 14 / 0.1=1400$ and not finding expected cell counts $<5[40]$.

The results of the multivariate logistic regression analyses of potential predictors of participation revealed that our model performed well with a significant goodness of fit $\left(\chi^{2}(26)=615.414, p<0.01\right)$. The fit of our model was good with Pseudo $\mathrm{R}^{2}$ being 0.40 (Table 4). Differences between participants and refusers were primarily explained by prosocial intrapersonal characteristics, while demographic characteristics provided only limited explanation. Notably, in our model, having a (registered) partner and a low educational level were relevant but slightly weaker predictors among the demographic variables. Low educational level significantly increased the odds to be participant in Lifelines in comparison with moderate or high educational levels, while a high level compared to moderate and low level of education had a smaller yet significant effect. In contrast, residence did not any longer contribute to differences between participants and refusers, once other predictors were taken into account $(\mathrm{OR}=0.76, p=0.10)$. A higher self-reported health significantly predicted participation in our model $(\mathrm{OR}=1.28, p=0.02)$.

Healthspheric values were the strongest predictors of participation in the simultaneous analyses of demographic and psychological predictors. This finding is reflected in the significant predictors of blood donor status $(\mathrm{OR}=2.31, p<$ $0.01)$ and organ donor status $(1.94, p<0.01)$. The lower scores in biospheric values of participants compared to refusers were robust in our multivariate analyses (3.76 vs. 3.83, $p<0.01$ ). Table 4 shows that associations of SVO score $(\mathrm{OR}=1.00, p=0.37)$ and frequency of charitable donations $(\mathrm{OR}=1.10, p=0.20)$ with participation in the univariate analyses were not robust in the multivariate model. Although societal trust as well as trust in data management and handling by the government independently contributed to the prediction of participation, the level of trust in data management and handling by commercial researchers was a key predictor of participation $(\mathrm{OR}=0.57, p=0.01)$. There is a clear lack of trust among participants, while refusers seem to have less issues in trusting commercial researchers and personal data.

\section{Discussion}

In this study, we examined demographic and psychological predictors of (non-)participation within a comparative analysis of biobank's participants and refusers. The results indicated that prosocial intrapersonal variables were stronger predictors of participation in biobanking than demographic variables. Specifically, health-related values and trust in management and handling of data by researchers appeared as key factors in distinguishing participants from refusers.

Our results add to previous findings on the importance of prosocial values and societal trust in participation in biobanking $[3,4,6,13,18,41]$. The appraisal of the context of biobanking, that is reflected in prosocial values and trust in society or government, was a key factor for participation. First, we found opposite associations of healthspheric and biospheric values with participation. This indicates that refusers prioritize health or healthcare differently. The differences in donor status for blood or organs support this explanation, since the odds ratio to be blood or organ donor was smaller for refusers. Even though studies showed that motives for research participation are prosocial [18, 42], we did not find a stronger general "prosociality" score of participants compared to refusers when taking into account all other factors. Similarly, a recent psychological study with college majors found associations of organ donation with a medicine major, but only positive trends for prosocial SVO score [43].

Second, the opposite associations of trust in data management and handling of government and of commercial researchers with participation suggest that trust could simultaneously work as facilitator and barrier for participation in biobanking depending on the context. Refusers in our study had less societal trust yet more trust in 
Table 4 Results of the logistic regression of participants and refusers of the Lifelines biobank.

\begin{tabular}{|c|c|c|c|c|c|}
\hline Variable & Step & OR & $95 \%$ CI OR & $p$ & $\begin{array}{l}\text { Pseudo } R^{2}\left[R^{2} \text { Cox and }\right. \\
\left.\text { Snell; } R^{2} \text { Nagelkerke }\right]\end{array}$ \\
\hline Age & 1 & 1.01 & {$[1.00,1.02]$} & $=0.09$ & {$[0.03 ; 0.06]$} \\
\hline Gender & 1 & 0.90 & {$[0.68,1.19]$} & $=0.45$ & \\
\hline Marital status & 1 & 1.68 & {$[1.24,2.28]$} & $<0.01$ & \\
\hline $\begin{array}{l}\text { Educational level } \\
\text { High vs. other }\end{array}$ & 1 & 0.58 & {$[0.42,0.79]$} & $<0.01$ & \\
\hline $\begin{array}{l}\text { Educational level } \\
\text { Low vs. other }\end{array}$ & 1 & 1.77 & {$[1.16,2.71]$} & $<0.01$ & \\
\hline Paid job $($ yes $=1$, no $=0)$ & 1 & 1.32 & {$[094,1.85]$} & $=0.11$ & \\
\hline Religious (yes $=1$, no $=0$ ) & 1 & 1.06 & {$[0.79,1.41]$} & $=0.72$ & \\
\hline Residence $($ rural $=1$, urban $=2$ ) & 1 & 0.81 & {$[0.58,1.12]$} & $=0.20$ & \\
\hline Self-reported health & 1 & 1.28 & {$[1.04,1.57]$} & $=0.02$ & \\
\hline Frequency of charitable donations & 2 & 1.10 & {$[0.95,1.27]$} & $=0.20$ & {$[0.04 ; 0.07]$} \\
\hline Blood donor & 3 & 2.31 & {$[1.35,3.94]$} & $<0.01$ & {$[0.04 ; 0.08]$} \\
\hline Organ donor & 4 & 1.94 & {$[1.45,2.58]$} & $<0.01$ & {$[0.05 ; 0.10]$} \\
\hline Social Value Orientation score & 5 & 1.00 & {$[1.00,1.01]$} & $=0.37$ & {$[0.05 ; 0.10]$} \\
\hline Healthsperic values & $6 a$ & - & - & $=0.02$ & {$[0.11 ; 0.20]$} \\
\hline Healthsperic values ${ }^{2}$ & $6 \mathrm{~b}$ & & & $<0.01$ & {$[0.13 ; 0.25]$} \\
\hline Healthsperic values ${ }^{3}$ & $6 c$ & & & $<0.01$ & {$[0.14 ; 0.27]$} \\
\hline Hedonic values & $7 \mathrm{a}$ & - & - & $<0.01$ & {$[0.15 ; 0.28]$} \\
\hline Hedonic values ${ }^{2}$ & $7 b$ & & & $<0.01$ & {$[0.17 ; 0.33]$} \\
\hline Biospheric values & $8 \mathrm{a}$ & - & - & $<0.01$ & {$[0.18 ; 0.35]$} \\
\hline Biospheric values ${ }^{2}$ & $8 b$ & & & $<0.01$ & {$[0.19 ; 0.36]$} \\
\hline Societal trust & 9 & 1.38 & {$[1.08,1.77]$} & $<0.01$ & {$[0.19 ; 0.37]$} \\
\hline TDM\&H/government & $10 \mathrm{a}$ & - & - & $<0.01$ & {$[0.20 ; 0.38]$} \\
\hline TDM\&H/government ${ }^{2}$ & $10 \mathrm{~b}$ & & & $<0.01$ & {$[0.20 ; 0.38]$} \\
\hline TDM\&H/commercial enterprises & 11 & 0.75 & {$[0.61,0.93]$} & $<0.01$ & {$[0.20 ; 0.38]$} \\
\hline TDM\&H/commercial researchers & 12 & 0.57 & {$[0.45,0.73]$} & $<0.01$ & {$[0.21 ; 0.40]$} \\
\hline
\end{tabular}

Test statistics multivariate model final step: $\chi^{2}(26)=615.414, p<0.01$.

$O R$ odds ratio (not reported if transformated), $C I$ confidence interval. commercial researchers compared to participants. This lower variance in refusers' trust in public vs. private context might indicate a more sceptic yet homogenic perception regardless of context. Two other studies found similar variances of trust in these contexts among non-participants $[5,30]$. Moreover, our results extend findings of a recent international comparison of trust and intention to participate in genomic research and big data initiatives, since we show how participants and refusers perceive systems of authority differently, especially in research [5,6]. Our findings argue for a context-specific understanding of trust [30, 44]. Similar to previous findings, trust in biobanks depended on its context, e.g., biobanks' funding stream or accessibility for third-party researchers [3, 4, 6, 45].

In our analyses, only educational level and being with partner were relevant demographic predictors of participation when taking into account prosocial intrapersonal characteristics. This supports previous findings on associations of participation with higher educational level and having a marital status [4-6]. First, a recent multinational study about genetic data sharing showed a similar effect for marital status on participation intention [6]. Recruitment aiming to include hereditability might be more prone for inclusion of citizens with partner. Recruitment strategies need to address this bias separately, given its robust effect in our multivariate model.

Second, we found that a higher education was associated with a higher probability of refusing to participate, regardless of levels of trust. This finding contradicts the literature showing that higher educational level is associated with participation [5, 6], yet confirms a recent study showing a highest willingness to participate in biobank research for middle educational level [22]. Possibly, our finding can be explained as a methodological issue, since the refusers sample underrepresented low educational level, while the participants sample represented this group more accurately. It is, however, also possible that psychological or social mechanisms explain this finding; samples with a mandatory sampling strategy provide better representativeness than voluntary samples [46]. The peer/family pressure for three generations of one family participating in Lifelines might have given the Lifelines' sample a mandatory character, which was not the case for the refusers panel. Another explanation might be a variance in motives for (non-)participation among higher and lower educated people, or a relevant variance in their social networks, including other people participating. Future research should investigate how educational level and marital status independently might 
affect participation and refusal of participation via these or other psychological or social factors.

\section{Implications}

Our findings suggest that biobanks seeking to recruit participants should consider multiple prosocial intrapersonal characteristics within their recruitment strategies. Our findings indicate that healthspheric, biospheric values and trust in government are strongly associated with participation in large-scale biomedical research. Therefore, emphasizing contextual prosocial benefits of participation and increasing the trustworthiness of biobanks as being independent from the government may facilitate the recruitment of new participants.

To retain participants, it may be wise to be cautious regarding collaborations with commercial enterprises because of participants' distrust of commercial researchers. The lack of trust in commercial enterprises is a general concern for recruitment and retention of participants. Our results highlight the importance of establishing governance and accountability structures that enhance trust in the biobanking context [45]. Solutions might be found in introducing trustworthy researchers as gatekeepers to data, in particular hospital researchers [6]. Although the role of societal trust has been acknowledged, research practices that strengthen trust in different private and public contexts merit greater attention. This consideration is particularly pressing in the field of personalized medicine, in which the collaborative management and handling of data, entailing diverse contexts, have sparked serious concerns over data use [18, 29].

\section{Limitations}

Although our study has provided insights into differences between participants and refusers of medical research, it has some limitations. Sampling bias may have occurred, as individuals who refused to participate in the biobank were nevertheless willing to complete an online questionnaire on this topic. Consequently, they may not be representative of all individuals unwilling to participate in biobanks or data repositories. Our sample of refusers was experienced and aware of commercial research or the procedures for research in general, which may explain their higher levels of trust in commercial researchers [4]. Nevertheless, our findings provide valuable inputs for recruitment strategies and effective methods for data repository.

\section{Conclusion}

In conclusion, we have shown that participants and refusers of biobanking can be distinguished according to their prosocial intrapersonal characteristics. Our findings may contribute to improving recruitment strategies by incorporating relevant values and/or highlighting prosocial benefits. Moreover, they underline the need to address trust issues in collaborations between data repositories and commercial companies. Future research should explore how prosocial intrapersonal characteristics drive participation and withdrawal decisions.

Acknowledgements We thank the editor and reviewers for their help. Moreover, we thank Lifelines for its collaboration in this study. Lifelines is a multidisciplinary, prospective population-based cohort study that has developed a unique three-generational design for examining the health and health-related behaviours of individuals living in the northern Netherlands. Lifelines applies a broad range of investigative procedures for assessing the biomedical, sociodemographic, behavioural, physical and psychological factors, with a particular focus on multi-morbidity and complex genetics.

Funding This study was supported by the Dutch Research Council (Grant No. 313-99-313).

\section{Compliance with ethical standards}

Conflict of interest The authors declare that they have no conflict of interest.

Ethical approval The Medical Ethics Review Board of the University Medical Center Groningen exempted this study from the ethics review according to the Medical Research Involving Human Subjects Act of the Netherlands, as it did not involve collection of any health-related data. Our study is conducted in line with all international, national and institutional ethical standards for scientific research.

Informed consent All respondents provided written informed consent for their participation.

Publisher's note Springer Nature remains neutral with regard to jurisdictional claims in published maps and institutional affiliations.

Open Access This article is licensed under a Creative Commons Attribution 4.0 International License, which permits use, sharing, adaptation, distribution and reproduction in any medium or format, as long as you give appropriate credit to the original author(s) and the source, provide a link to the Creative Commons license, and indicate if changes were made. The images or other third party material in this article are included in the article's Creative Commons license, unless indicated otherwise in a credit line to the material. If material is not included in the article's Creative Commons license and your intended use is not permitted by statutory regulation or exceeds the permitted use, you will need to obtain permission directly from the copyright holder. To view a copy of this license, visit http://creativecommons. org/licenses/by/4.0/.

\section{References}

1. Rivera SM, Brothers KB, Cadigan RJ, Harrell HL, Rothstein MA, Sharp RR, et al. Modernizing research regulations is not enough: it's time to think outside the regulatory box. Am J Bioeth. 2017;17:1-3. https://doi.org/10.1080/15265161.2017.1328899.

2. Mittelstadt BD, Allo P, Taddeo M, Wachter S, Floridi L. The ethics of algorithms: mapping the debate. Big Data Soc 2016;2016:68. https://doi.org/10.1177/2053951716679679. 
3. Gaskell G, Gottweis H, Starkbaum J, Gerber MM, Broerse J, Gottweis U, et al. Publics and biobanks: Pan-European diversity and the challenge of responsible innovation. Eur J Hum Genet. 2013;21:14-20. https://doi.org/10.1038/ejhg.2012.104.

4. Critchley C, Nicol D, Otlowski M. The impact of commercialisation and genetic data sharing arrangements on public trust and the intention to participate in biobank research. Public Health Genomics. 2015;18:160-72. https://doi.org/10.1159/000375441.

5. Middleton A, Milne R, Thorogood A, Kleiderman E, Niemiec E, Prainsack B, et al. Attitudes of publics who are unwilling to donate DNA data for research. Eur J Med Genet. 2019;62:316-23. https://doi.org/10.1016/j.ejmg.2018.11.014.

6. Milne R, Morley KI, Howard H, Niemiec E, Nicol D, Critchley C, et al. Trust in genomic data sharing among members of the general public in the UK, USA, Canada and Australia. Hum Genet. 2019;138:1237-46. https://doi.org/10.1007/s00439-019-02062-0.

7. Thompson A. Thinking big: large-scale collaborative research in observational epidemiology. Eur J Epidemiol. 2009;24:727-31. https://doi.org/10.1007/s10654-009-9412-1.

8. Kettis-Lindblad Å, Ring L, Viberth E, Hansson MG. Genetic research and donation of tissue samples to biobanks. What do potential sample donors in the Swedish general public think? Eur J Public Health. 2006;16:433-40. https://doi.org/10.1093/eurpub/ cki198.

9. Critchley C, Nicol D, Otlowski M, Stranger M. Predicting intention to biobank: a national survey. Eur J Public Health. 2012;22:139-44. https://doi.org/10.1093/eurpub/ckq136.

10. Ahram M, Othman A, Shahrouri M, Mustafa E. Factors influencing public participation in biobanking. Eur J Hum Genet. 2014;22:445-51. https://doi.org/10.1038/ejhg.2013.174.

11. Kaufman D, Murphy J, Scott J, Hudson K. Subjects matter: a survey of public opinions about a large genetic cohort study. Genet Med. 2008;10:831-9. https://doi.org/10.1097/GIM. 0b013e31818bb3ab.

12. Klijs B, Scholtens S, Mandemakers JJ, Snieder H, Stolk RP, Smidt N. Representativeness of the LifeLines cohort study. PLoS ONE. 2015;10:1-12. https://doi.org/10.1371/journal.pone. 0137203.

13. Sanderson SC, Brothers KB, Mercaldo ND, Clayton EW, Antommaria AHM, Aufox SA, et al. Public attitudes toward consent and data sharing in biobank research: a large multi-site experimental survey in the US. Am J Hum Genet. 2017;100:414-27. https://doi.org/10.1016/j.ajhg.2017.01.021.

14. Merdad L, Aldakhil L, Gadi R, Assidi M, Saddick SY, Abuzenadah A, et al. Assessment of knowledge about biobanking among healthcare students and their willingness to donate biospecimens. BMC Med Ethics. 2017;18:32. https://doi.org/10.1186/ s12910-017-0195-8.

15. Rahm AK, Wrenn M, Carroll NM, Feigelson HS. Biobanking for research: a survey of patient population attitudes and understanding. J Community Genet. 2013;4:445-50. https://doi.org/10. 1007/s12687-013-0146-0.

16. Ridgeway JL, Han LC, Olson JE, Lackore KA, Koenig BA, Beebe TJ, et al. Potential bias in the bank: what distinguishes refusers, nonresponders and participants in a clinic-based biobank? Public Health Genomics. 2013;16:118-26. https://doi.org/ $10.1159 / 000349924$

17. Goddard KABB, Smith KS, Chen C, McMullen C, Johnson C. Biobank recruitment: motivations for nonparticipation. Biopreserv Biobank. 2009;7:119-21. https://doi.org/10.1089/bio.2009.0006.

18. Richter G, Borzikowsky C, Lieb W, Schreiber S, Krawczak M, Buyx A. Patient views on research use of clinical data without consent: legal, but also acceptable? Eur J Hum Genet. 2019;27:841-7. https://doi.org/10.1038/s41431-019-0340-6.

19. Luhmann N. Trust and power. John Wiley \& Sons Inc.; 1979. p. 228.
20. Rotter JB. Generalized expectancies for interpersonal trust. Am Psychol. 1976;26:443-52.

21. Porteri C, Pasqualetti P, Togni E, Parker M. Public's attitudes on participation in a biobank for research: an Italian survey. BMC Med Ethics. 2014;15:81. https://doi.org/10.1186/14726939-15-81.

22. Bossert S, Kahrass H, Strech D. The public's awareness of and attitude toward research biobanks - A regional German survey. Front Genet. 2018;9:1-11. https://doi.org/10.3389/fgene.2018. 00190.

23. Critchley C, Nicol D, McWhirter R. Identifying public expectations of genetic biobanks. Public Underst Sci. 2017;26:671-87. https://doi.org/10.1177/0963662515623925.

24. Hyde MK, Knowles SR. What predicts Australian university students' intentions to volunteer their time for community service? Aust J Psychol. 2013;65:135-45. https://doi.org/10.1111/ajpy. 12014.

25. van der Werff E, Steg L. The psychology of participation and interest in smart energy systems: comparing the value-belief-norm theory and the value-identity-personal norm model. Energy Res Soc Sci. 2016;22:107-14. https://doi.org/10.1016/j.erss.2016.08.022.

26. Bouman T, Steg L, Kiers HAL. Measuring values in environmental research: a test of an environmental portrait value questionnaire. Front Psychol 2018;9:1-15. https://doi.org/10.3389/ fpsyg.2018.00564.

27. Steg L, Perlaviciute G, van der Werff E, Lurvink J. The significance of hedonic values for environmentally relevant attitudes, preferences, and actions. Environ Behav. 2014;46:163-92. https:// doi.org/10.1177/0013916512454730.

28. Evers A, Gesthuizen M. The impact of generalized and institutional trust on donating to activist, leisure, and interest organizations: Individual and contextual effects. Int J Nonprofit Volunt Sect Mark. 2011;16:381-92. https://doi.org/10.1002/nvsm.434.

29. Raivola V, Snell K, Helén I, Partanen J. Attitudes of blood donors to their sample and data donation for biobanking. Eur J Hum Genet. 2019;27:1659-67. https://doi.org/10.1038/s41431-019-0434-1.

30. Broekstra R, Aris-Meijer J, Maeckelberge E, Otten S, Stolk R. Trust in centralised large-scale data repository: a qualitative analysis. J Empir Res Hum Res Ethics. 2019:1-14. https://doi.org/10. $1177 / 1556264619888365$.

31. Mújdricza F. The roots of trust. Eur J Ment Heal. 2019;14:109-42. https://doi.org/10.5708/EJMH.14.2019.1.6.

32. Scholtens S, Smidt N, Swertz MA, Bakker SJLL, Dotinga A, Vonk JM, et al. Cohort profile: LifeLines, a three-generation cohort study and biobank. Int J Epidemiol. 2015;44: $1172-80$

33. Messick DM, McClin, McClintock CG. Motivational bases of choice in experimental games. J Exp Soc Psychol. 1968;4:1-25. https://doi.org/10.1016/0022-1031(68)90046-2.

34. Murphy RO, Ackermann KA, Handgraaf MJJ. Measuring social value orientation. Judgm Decis Mak. 2011;6:771-81. https://doi. org/10.2139/ssrn. 1804189.

35. Schwartz SH, Cieciuch J, Vecchione M, Davidov E, Fischer R, Beierlein $\mathrm{C}$, et al. Refining the theory of basic individual values. $\mathrm{J}$ Pers Soc Psychol. 2012;103:663-88. http://doi.apa.org/getdoi. cfm?doi=10.1037/a0029393.

36. Mayer RC, Davis JH, Schoorman FD. An integrative model of organizational trust. Acad Manag Rev. 1995;20:709-34. http://www.jstor.org/stable/258792.

37. IBM Corp. IBM SPSS statistics for Windows, version 25.0. Armonk, NY: IBM Corp.; 2017.

38. Hair JF, Black WC, Babin BJ, Anderson RE. Multivariate data analysis. 7th ed. Pearson Prentice Hall; 2014. p. 734.

39. Box GEP, Tidwell PW. Transformation of the independent variables. Technometrics. 1962;4:531-50. https://www.tandfonline. com/doi/abs/10.1080/00401706.1962.10490038. 
40. Peduz P, Concato J, Kemper E, Holford TR, Feinstein AR. Study of the number of events per variable. Logist Regres Anal. 1996;49:1373-9.

41. Gayet-Ageron A, Rudaz S, Perneger T. Biobank attributes associated with higher patient participation: a randomized study. Eur J Hum Genet. 2016;25:31-6. https://doi.org/10.1038/ejhg.2016.132.

42. Locock L, Boylan AMR. Biosamples as gifts? How participants in biobanking projects talk about donation. Heal Expect. 2016;19:805-16. https://doi.org/10.1111/hex.12376.

43. van Andel CEE, Tybur JM, Van Lange PAM. Donor registration, college major, and prosociality: differences among students of economics, medicine and psychology. Pers Individ Dif. 2016;94:277-83. https://doi.org/10.1016/j.paid.2016.01.037.
44. Sheikh Z, Hoeyer K. "That is why I have trust": unpacking what 'trust' means to participants in international genetic research in Pakistan and Denmark. Med Heal Care Philos. 2018;21:169-79. https://doi.org/10.1007/s11019-017-9795-9.

45. Nicol D, Critchley C, McWhirter R, Whitton T. Understanding public reactions to commercialization of biobanks and use of biobank resources. Soc Sci Med. 2016;162:79-87. https://doi.org/ 10.1016/j.socscimed.2016.06.028.

46. Cheung KL, Ten Klooster PM, Smit C, De Vries H, Pieterse ME. The impact of non-response bias due to sampling in public health studies: a comparison of voluntary versus mandatory recruitment in a Dutch national survey on adolescent health. BMC Public Health. 2017;17:1-10. https://doi.org/10.1186/s12889-017-4189-8. 